\title{
Histological Sublethal Concentration Effect on the Liver of Clarias Batrachus (Linn.) Exposed To Malathion

\author{
Ashutosh Diwakar, Devendra Pandey
}

\begin{abstract}
Malathion is a vital agent and indicator that kills targeted (harmful) organic of flora and fauna. Word 'pest' has comprised of detrimental animals, plants and microorganisms. These are widely used all over the world in agriculture. several agricultural pesticides nowadays in the trend in which organisms toxicity and harmful alterations are noticeable. Malathion pesticides used as agricultural benefits for crop production. This type of pesticide mostly affects the histological and biochemical parameters of the organism. This study focuses on alterations of malathion observing special site tissues of freshwater fish Clarias batrachus (Linn.,1758). Malathion (50\% EC) was ordered from super ford insecticides limited, Sikandrabad (BSR) and a volumetric practical performed to result out the LC50 96 hours of malathion. Value of malathion LC50 96 hours calculated 0.25 ppm. The SLC as 0.025 parts per million was fixed by using 1/10th of LC50 at 96 hours [1]. The effect of malathion SLC (1/10 of 96 hours of LC50) was investigated on the histology of the liver in treated groups of host fish. Specific changes were checked in liver histology using control and treated groups. Histological observations as hepatocytes degeneration, Necrosis in hepatocytes, vacuolar degeneration, congestion were recorded and analyses as per experimental requirement. The main objective of this article is to carry out a histological study to check the impacts of the Sublethal concentration of Malathion (EC50\%) on the liver of "Clarias batrachus."
\end{abstract}

Keywords: Histological, Acute toxicity, Liver, Freshwater fish, Clarias batrachus, Malathion.

\section{INTRODUCTION}

Malathion, an agricultural pesticide is being worldwide used as powder and vapor to control various types of harmful insects and pests. SLC dose of Malathion (EC50\%) shows different toxic changes on freshwater fish. Malathion used in agriculture should be strictly controlled by legislation and prevent its bioaccumulation in aquatic animals [2].

Sakakushi (1972) stated liver dysfunction and hepatic necrosis in host fish under Malathion stress [3]. Dutta et al. (1994) also stated noticeable microscopic alterations in ovigerous lamellae, oocytes at various stages of development and the nucleus of the immature oocyte of the catfish Heteropneustes fossilis [4].

Revised Manuscript Received on March 10, 2020.

* Correspondence Author

Ashutosh Diwakar*, Department of Zoology, Bundelkhand University, Jhansi, India. Email: ashutoshdiwakar.ft@gmail.com

Devendra Pandey, Department of Zoology, Bundelkhand University, Jhansi, India. Email: drdevendrapandey@gmail.com

(C) The Authors. Published by Blue Eyes Intelligence Engineering and Sciences Publication (BEIESP). This is an open access article under the CC BY-NC-ND license (http://creativecommons.org/licenses/by-nc-nd/4.0/)
The academic projects revealed that the impact of the lower dose of malathion pesticide on freshwater catfish Clarias batrachus is still very little. This article is focused to study the "Histological SLC dose of malathion toxicity On liver of Fresh Water Fish Clarias batrachus".

Recently, in the agriculture field the pesticides effects on freshwater fish as resulting physiological and biochemical pushiness of these organics in the food chain causing detrimental effects on biomarkers of aquatic fauna [5].

In the tissue of organisms, pesticide plays the role of many histological and biochemical changes in their bodies and cause many metabolically changes. Due to the appearance of several enzymes and metabolites finally causes the whole metabolic mechanism disturbance [6].

A kind of biomarker not only permits examining the specific site of issues that are due to vital functions and provides physiological exposure regarding the adverse effect of animal health [7].

A huge account of pesticides is basically used to control various agricultural pests; although, their toxicological changes also reveals to nonspecific organisms like fish [8]. Fish is a good bio-indicator of aquatic pollution cause of its biochemical stress responses are similar to those found in mammals [9].

Toxicological experiments have illustrated that malathion affected liver and blood. In the current study effects of malathion were performed and variation in the liver was studied.

\section{MATERIALS AND METHODS}

The current study has been envisioned to find out the impact of the SLC dose of Malathion (50\% EC) on the liver of Clarias batrachus (Linnaeus, 1758). Healthy and mature fishes Clarias batrachus, commonly called magur of the same size $(12 \pm 3 \mathrm{~cm})$ and mean weight (100-150 gm) are purchased from the nearest fish market. These were carefully examined for any injury and then kept in a $1 \% \mathrm{KMnO} 4$ solution for a few minutes to get rid of any dermal infection. fishes were acclimatized in a fish aquarium containing 60 liters of freshwater at $25 \pm 2^{\circ} \mathrm{C}$ temperature and fed on a boiled egg and fish food.

These were acclimatized for 20 days in a laboratory-controlled environment before the commencement of the experiment. Fishes were kept hungry before 24 hours according to the experimental protocol and were not fed during the experimental period [10]. 
Malathion (50\% EC) was ordered from super ford insecticides limited, Sikandrabad (BSR). LC50 96 hours value of malathion was determined. The SLC dose of 0.025 parts per million calculated by 1/10th of LC50 at 96 hours [1].

Experimental parameters of water which was taken for the experiment were $\mathrm{pH} 6.4 \pm .04$, DO $7.8 \pm 0.32 \mathrm{mg} / \mathrm{l}$ and temp. $28 \pm 0.470$ C. The liver was separated, dissected and kept in 1 $\mathrm{N}$ formaldehyde for one day, then dehydrated, embedded in paraffin and sections were cut at 5-micrometer thick and stained with Harris's hematoxylin and eosin dye. Prepared microscopic slides were investigated under the compound microscope and microphotographs were captured.

The fishes group were separated into two groups (group 1 and 2) in a fish aquarium. 15 fishes were taken in each group. SLC of malathion (50\% EC) was given to group 2nd under 45 days. Group 1st fishes were rared in normal water as the control group. After the malathion dose, both groups of fishes were sacrificed to toxicity exposure at the end of the 45th day. Tissues of the liver were separated and kept in Bouin's fluid. After 24-30 hours, selected tissues were dehydrated using a series of ethanol grades, cleaned in absolute xylene, and fixed in the paraffin histowax. Sections of 5 micrometers were built by using a precision microtome. The sections of the liver of host fishes were stained with Harris' Hematoxylin and Eosin dye and mounted in Canada balsam and observed under a compound microscope.

\section{RESULTS AND DISCUSSION}

The lymphoid organ liver acts as detoxification and bioindicator for the physiology of the body. Due to the digestive function, this organ directly involved in sensory indication for histological response to contaminants in food and water [11]. Histological analysis of the control host in this experiment presents hepatocytes without any changes. In the control group, liver tissues and hepatic cells were observed clearly (Plate-1). After exposure to malathion (50\% EC), Clarias batrachus liver had many histological changes. The decomposition of blood vessels found in hemorrhagic sites. Vacuolar degeneration was recorded in the liver after malathion treatment (Plate-4). Histological changes are seen because of metabolic disfunction by exposure of pesticide affected water [12]. Cellular congestion has resulted in this current study (Plate-5).

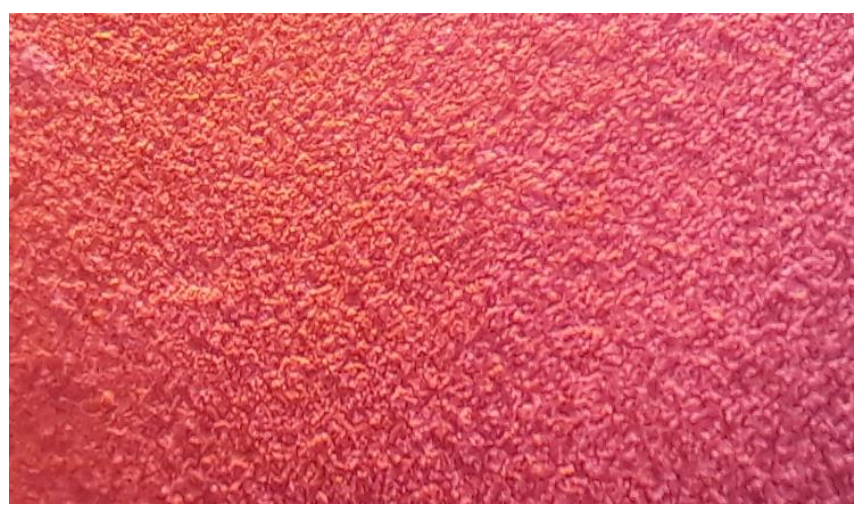

Plate-1. Control liver tissue of Clarias batrachus (100X)

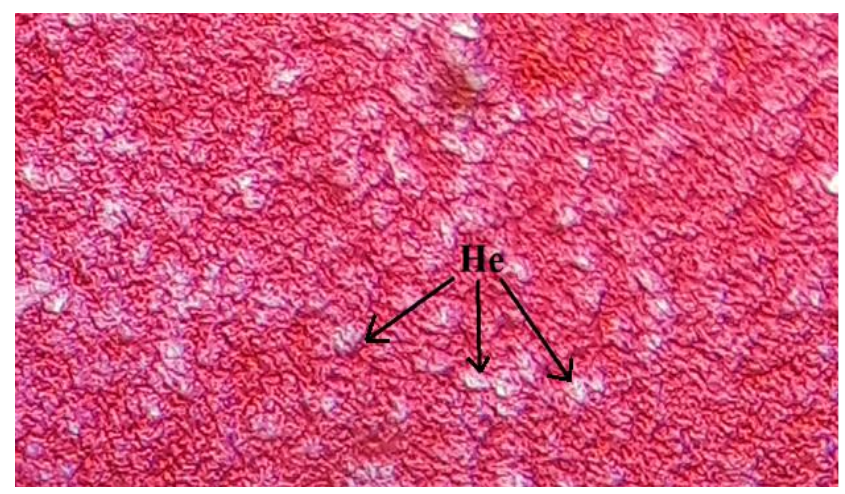

Plate-2. Clarias batrachus treated liver after malathion SLC Dose showing hepatocytes degeneration (100X)

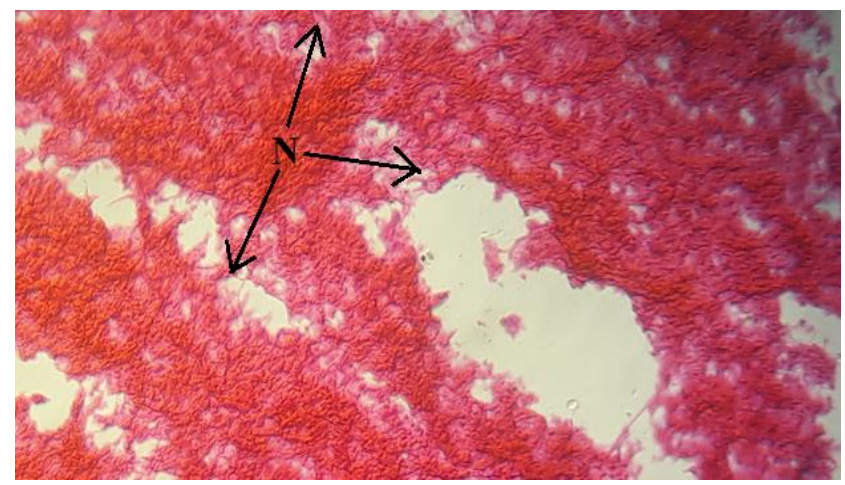

Plate-3. Malathion treated liver of Clarias batrachus showing Necrosis in hepatocytes $(100 \mathrm{X})$

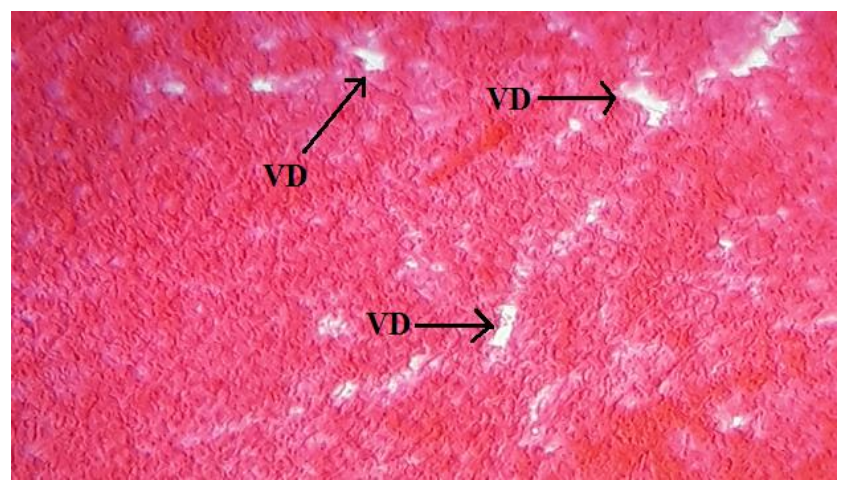

Plate-4. Malathion treated liver of Clarias batrachus showing Vacuoler degeneration (100X)

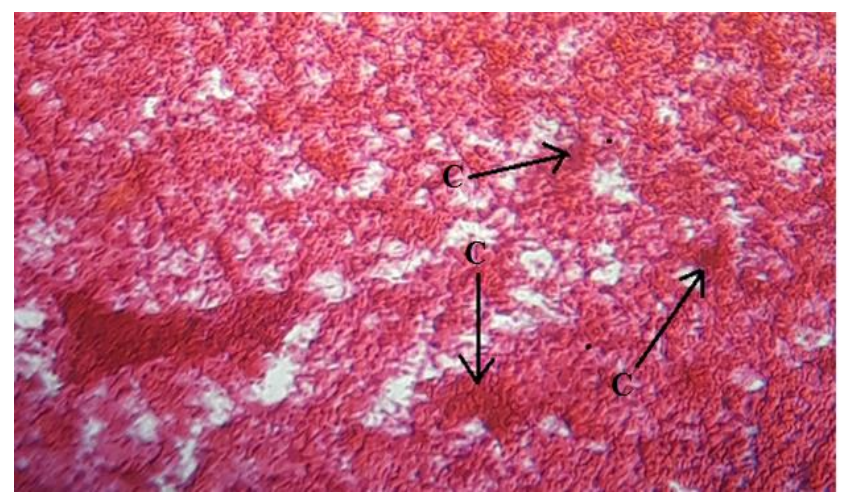

Plate-5. Malathion treated liver of Clarias batrachus showing congestion (100X)

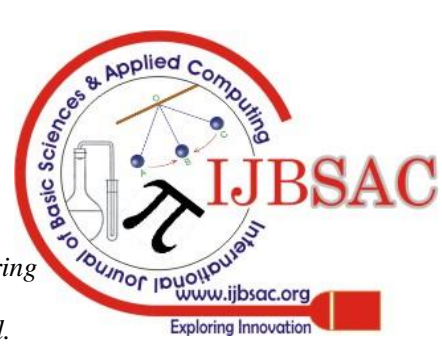


Table- I: Explanation of plate with observation.

\begin{tabular}{|l|l|}
\hline Plate & Exposure/Observations \\
\hline $\begin{array}{l}\text { Plate } \\
1 .\end{array}$ & Control liver tissue of Clarias batrachus (100X) \\
\hline $\begin{array}{l}\text { Plate } \\
2 .\end{array}$ & $\begin{array}{l}\text { Clarias batrachus treated liver after malathion SLC Dose } \\
\text { showing hepatocytes degeneration (100X) }\end{array}$ \\
\hline $\begin{array}{l}\text { Plate } \\
3 .\end{array}$ & $\begin{array}{l}\text { Malathion treated liver of Clarias batrachus showing } \\
\text { Necrosis in hepatocytes (100X) }\end{array}$ \\
\hline $\begin{array}{l}\text { Plate } \\
4 .\end{array}$ & $\begin{array}{l}\text { Malathion treated liver of Clarias batrachus showing } \\
\text { Vacuoler degeneration (100X) }\end{array}$ \\
\hline $\begin{array}{l}\text { Plate } \\
5 .\end{array}$ & $\begin{array}{l}\text { Malathion treated liver of Clarias batrachus showing } \\
\text { congestion (100X) }\end{array}$ \\
\hline
\end{tabular}

\section{CONCLUSION}

In this study, it has resulted that the SLC dose of malathion (50\%EC) was effected to find out a large number of histological changes in Clarias batrachus liver. Histological changes like vacuolar degeneration, hepatocytes degeneration, congestion, and necrosis were found and explained with malathion affected toxicity in host fish.

\section{ACKNOWLEDGMENT}

The authors are thankful to the HOD, Department of Zoology, Bundelkhand University Campus, Jhansi (U.P.) for providing the experimental facilities and laboratory support.

\section{REFERENCES}

1. Yogesh. "Sublethal and Chronic Effect of Carbaryl and Malathion on Clarias batrachus (Linn.)”. J. Appl. Sci. Environ. Manage. Vol. 13(2), 2009, pp. 23-26.

2. Diwakar, A., Tripathi, R., Pandey, D. and Khatoon, R. "Toxic effect of malathion on Clarias batrachus". JETIR, (online) Volume-6, Issue-6. ISSN- 2349-5162, 2019.

3. Sakakushi, H., Bull. Tap. Soc.Sci.Fish., 1972, 38: 555.

4. Dutta H. M., Nath A., Adhikari S., Roy P. K., Singh N. K. and Munshi J. S. D. "Sublethal Malathion induced changes in the ovary of an air-breathing fish, Heteropneustes fossilis a histological study". Hydrobiologia, 1994, 294 (3): pp. 215-218.

5. Yu Zhang, Jiao An, Wei Ye, Guangyu Yang, Zhi-Gang Qian, Hai-Feng Chen, Li Cui, and Yan Feng (2012), "Enhancing the Promiscuous Phosphotriesterase Activity of a Thermostable Lactonase (GkaP) for the Efficient Degradation of Organophosphate Pesticides", Applied and Environmental Microbiology, 78(18), 2012, pp. 6647-6655.

6. Mukesh K N. "The effect of pesticides on the fish fauna of Bhopal lower lake (M. P.). African Journal of Environmental Science and Technology", 7(7), 2013, pp. 725-727.

7. Hinton D.E. and Lauren D.J., "Liver structural alterations accompanying chronic toxicity in fishes: potential biomarkers of exposure". In: McCarthy, J.F. and Shugart L.R. (Eds.), Biomarkers of Environmental Contamination, Boca Raton, Lewis Publishers, 1993, pp. 51-65.

8. Naqvi, S. M.; Vaishnavi, C., "Bioaccumulative potential and toxicity of endosulfan insecticide to non-target animals". Comp. Biochem. Phys. C, 105, 1993, pp. 347-361.

9. Mishra, R.; Shukla, S. P., "Endosulfan effects on muscle malate dehydrogenase of the freshwater catfish Claria batrachus". Ecotox. Environ. Safe., 56, 2013, pp. 425-433.

10. Dalela R.C., Bhatnagar M.C., Tyagi A.K., \& Verma S.R. "Histological damage of gills in Channa gachua after acute and subacute exposure to endosulfan and Rogor". Mikroskopie (Vienna), 35: 1979, pp. 301-307.

11. Camargo M.M. and Martinez C.B. "Histopathology of gills, kidney, and liver of a Neotropical fish caged in an urban stream", Neutro. Ichthyol., 5, 1972: pp. 327-336.

12. Devi Y. and Mishra A. "Histopathological alterations in gill and liver anatomy of freshwater, air-breathing fish Channa punctatus after pesticide Hilban ${ }^{\circledR}$ (chlorpyrifos) treatment”, Adv. Biores., 4(2), 2013, pp. 57-62.

\section{AUTHORS PROFILE}

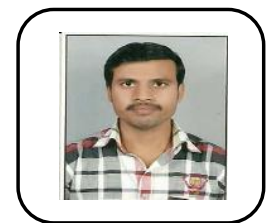

Ashutosh Diwakar (Senior Research Fellow), JRF, RGN-SRF (RGNF) Aquatic Toxicology Laboratory, Department of Zoology, Bundelkhand University Campus, Jhansi (U.P.)

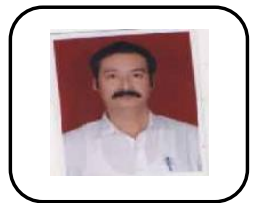

Devendra Pandey (Assistant Professor) Former Head of Department, Research Supervisor - Aquatic Toxicology Laboratory, Department of Zoology, Bundelkhand University Campus, Jhansi (U.P.)

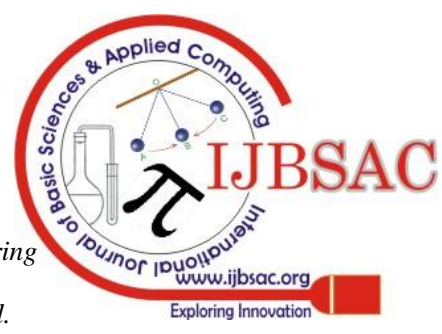

